\title{
Talking about Ancient Chinese Commercial Advertising Styles
}

\author{
Shengying Feng \\ Computer Department, Nanhua College of Industry and Commerce \\ Guangzhou 510000, China \\ E-mail: feng_shengying@126.com
}

\begin{abstract}
Ancient Chinese working people created a wide range of different advertising styles in the process of adapting themselves to and transforming nature, such as object ads, sound ads, sign ads, couplet ads, poetry ads, print ads and hall decoration ads, etc. These advertising forms reflect the folk customs of different stages of development and the ideology of all sectors of the ancient society and demonstrate a variety of advertising content and life information.
\end{abstract}

Keywords: Object ads, Sound ads, Sign ads, Couplet ads, Poetry ads, Print ads, Hall decoration ads

Human beings used simple chipped stones and polished stones, melt bronze and adopted iron tools. The labor efficiency had been continuously improved and the ability against nature enhanced too. The increased productivity and the surplus products provided the possibility for the exchanges of products and laid material foundation for the appearance of commercial advertising. This text will explore the styles or forms of commercial advertising in ancient China as the followings:

\section{Object ads for bartering}

Laborers of different walks of life will inevitably display their wares on the market for exchanges. The Book of Changes records,

"On the death of Bao-xi, there arose Shen-nong (in his place). He fashioned wood to form the share, and bent wood to make the plough-handle. The advantages of ploughing and weeding were then taught to all under heaven... He caused markets to be held at midday, thus bringing together all the people, and assembling in one place all their wares. They made their exchanges and retired, and every one having got what he wanted."

From the above passage, we can see that "all people under heaven" carried their wares from all directions to gather in one place to trade and everyone got what they wanted and the exhibition of objects becomes the essential link in this process.

With the rise of the cities, business began to boom. And object ads gradually evolved to object-suspended ads. According to MengLiangLu written by Wu Zimu of Song Dynasty, restaurants and hotels of Hangzhou city at that time suspended grass gourd, silver spoon or silver bowl for advertising, which all were tools for scooping wine. Li Song in his Peddler and Children and Su Hanchen in his Picture of Street Vendors of Song Dynasty all gave specific descriptions of the varieties of goods on the street booth.

There are many similar forms of advertising. And the simplest and most primitive form of advertising had been continued in ancient Chinese society for thousands of years. So far, the simple display still can be found in people's real life.

\section{Sound Ads use sound to attract customers}

Sound advertisement is a general term of three basic advertising forms of peddling, chiming and making noise to attract customers in ancient Chinese society. Peddling is one of the earliest forms of advertising. The other two forms of chiming and making noise develop from it.

The ancients continued to artistically adapt some monotonous selling skills in the long-term social and economic life. For example, art forms of poems or folk raps were borrowed with intonation and rhythm being melted to form a very rustic "intonating", which really expresses the interest and charm in extraordinary life and the features of what is sold.

The selling rap in rhymed words with a strong connotation and characteristics became popular in the Song Dynasty. 
There were varieties of rap forms in North and South Song Dynasty such as Changzhan, Xuexiangtan, Jiaoguzi and Xuexiangsheng, etc. These forms of Song Dynasty have been imitated repeatedly by the folk artists and gradually developed into a rap art welcomed by the common people. Origins of Objects says,

"If a thing is sold in the capital city, there must be rhymed sound in difference. Thus some city residents adopt the intonation and changed the words to make it become an enjoyable artistic form."

Some advertising forms of adopting folk artistic raps such as the tune of street vendors, of selling second-hand clothes, and of selling pear sugar, etc are more appropriately considered to be cultural advertisement more than commercial advertisement.

Of the different sounds of attracting customs, in addition to the oral raps, making sounds with phonate instruments is one of the means people adopt for advertising. Phonate instrument marketing has other names of Daisheng or Huosheng, which means using the sounds that the instruments produce to replace oral selling or an advertising means adopted together with the oral selling.

Sound advertisement has various forms in the ancient society. Its name alone contains a wealth of cultural content. For example, old Beijing has famous eight silences, that is, barber, doctor, domestic tools repairer, those dealing with Juwan and Xiujiao, shoe-repairer, fan -repairer, and duster seller, etc. Thus these titles are derived such as a ringing iron carried by the hair-cut peddlers is called as Huantou; a copper and iron ring used by the doctors is named as Hucheng; a small gong used by the blind men is known as Baojunzhi; a iron plate in the hand of a person who grinds mirrors is called Jinggui; a iron in the hand of a whitesmith is named as Naojie; a little gong hold by oil peddler is Chufangxiao; what food sellers hold is Quchan; and what the peddlers who sell things for girls is named Huanjiaoniang, etc. The above advertising forms, in addition to advertise their goods, reflect the rich cultural connotation and are marked with the deep imprint of the national culture.

\section{Insert Figure 1 Here}

\section{Sign ads}

The appearance of sign advertisements is directly related to the primitive totem worship. Its development is also closely linked to the differentiation of street selling and store selling. The sign advertisement, rich in folk culture, is the advertising form with the deepest national characteristics and is considered to be the carrier of ancient Chinese folk culture.

Shops in ancient times often suspended some pieces of cloths in front of the doors in order to attract the attention of customers, which are known as the signs. Sign advertisement often uses vivid images to express the good sold or services offered, easy for customers to accept. Sign advertisement probably can be divided into three types of image, symbol and word posters.

Image poster is to suspend a physical object for sale, or the amplified or the reduced model or just the picture of it to signify the features for advertising. The initial image poster is simple and intuitive. For example, a bast store hangs a bunch of bast. An image can be used to replace physical object, for example, a fish shop hangs several large wooden fish in front of the door to tell people that fish is sold here. Or using pictures replaces the physical objects, such as patterns of calabash or jar hung in front of a wine bar, etc. Because these posters have been used for quite a period, they have been gradually established to be the marks of the specific goods.

Symbol poster mainly refers to flag sign. Wine flags are usually in great number. Xin Qiji, the famous poet in South Song Dynasty wrote, "there are mountains in long or short distance, the cranking paths and the black flag indicates there are people who lives nearby". The black flag of the mountain tavern is the wine flag poster. Another form of symbol poster is the lantern advertisement. There are detailed descriptions in Pubs of Menglianglu, saying,

"For example, in front of pubs or restaurants, branches or gardenia lanterns are suspended probably because in Five Dynasties emperor Guo traveled in Bianjing, all the tea houses or pubs must have been decorated like these. And now pubs or restaurants still follow the established custom".

These words do not only show that in the period of emperor Guo of Five Dynasties, lantern advertisement turned up but also tell us that it was a custom in Song Dynasty for the tea houses or pubs or restaurants to suspend lanterns as posters to attract customers.

\section{Insert Figure 2 Here}

Written poster is considered to be the original form of signs or advertisements. It indicates the business category simply by using one or two Chinese characters and is usually hung in front of the door the same as other posters. In Pictures of Prosperous Jinling of the Ming Dynasty, a great number of written posters can be found, such as, posters of tea, wine, book, cap, medicine, and rice, etc. Patterns of clouds, money, dragon or happiness are adopted to decorate them to delight people. The color of posters is Chinese red to symbolize good luck, as bears rich folk characteristics. 


\section{Couplet ads with witty remarks}

Couplet advertisement is an artistic form of combining couplet technique and advertising expression. Couplet ads can be found in shops or stores, restaurants or tea houses. They together with the businesses managed can reflect the characteristics of the industry and bear distinctive ethnic features. Couplet ads are the organic combination of commercial culture and advertisement.

Couplets originate in spring couplets, which come from Tao Fu. Wang Anshi wrote a poem of New Year's Day, saying, "Thousands of households feel happy in the bright sun. The old magic figures are replaced by new ones in sight." Chen Yunzhan of the Qing Dynasty in his Zanyuanlou Essays wrote,

"Spring couplets were first established by Ming Taizu, the first emperor of Ming Dynasty. In the capital city, just on the eve of the spring festival, royal edict came saying that doors of officials and common people should be posted up spring couplets for the emperor to appreciate when going out."

The next day, Ming Taizu went out in casual clothes and appreciated the couplets door by door. When he got to a door and found there was no couplets on it, he asked the reason. It turned out that the host was a sow gelder and an illiterate. Ming Taizu immediately wrote down the following words of "splitting up the path of life and death with two hands, cutting down the root of right and wrong" and presented it to the gelder. This pair of couplets was vivid and humorous. It advertised for the sow gelder to improve his popularity and made people appreciate the beauty of the Chinese words.

Couplet advertising is a clever use of words, so many scholars show great interests in them. Tang Bohu, the famous No. 1 Jiangnan gifted man, once wrote a pair of couplets for a company. It is read "business is prosperous like spring grass; financial resources are similar to the water well". The famous calligrapher Zhu Zhishan wrote couplets for a wine restaurant of that "nothing is in my charge but the restaurant; just enjoy the wine whether it is prosperous or not". A good couplet ad can not only make people appreciate the beauty of the words, but also improve the popularity of the businesses.

A lot of businesses use couplets for advertising. For instance, one of the theater ads is something like "do not sit ahead for listening to the play is quite better than viewing it. A man should consider its next step for he can walk up stage and down the stage." The couplet advertisement of an antique shop says "playing with antiques but not indulged in them. Living with antiques is only for love."

\section{Poem advertisement makes excellent sentence and fine verse more famous}

Poem advertising is a more mature form of numerous ancient Chinese advertisements. It can be divided into two types. One is that ads are mentioned in a poem and the other is that poems are used to publicize the features of goods and services.

The great poet Li Bai of the Tang Dynasty in one of his poems wrote "The wine of Lanling is full of fragrance of tulips. The wine in the jade bowl reflects the color of amber. It helps the host to fully entertain his guests, making them lose their way home." It is probably by far the first poem ad that we can confirm.

In the period of Shaosheng of the Song Dynasty, Su Dongpo once wrote a poem ad for an old woman who sold Sanzi, a kind of Chinese food. It goes that "the stuff is kneaded to be like jade and fried in yellow oil. It becomes soft yellow like the bracelet around a beautiful lady." The poem describes the product's features. Together with Su Dongpo's celebrity, it has attracted a large number of customers and from then on, the old woman's business began to boom.

In the period of Daoguang of the Qing Dynasty, the poet Yang Jingting once wrote a poem, Capital Gate: A Hundred Poems. The Crystal Gao is one of them. It advertised for the crystal Gao of Shaoxing. It goes, "it has Shaoxing favor with nice technique. The material of glutinous rice is soft like cream. Sweet and light, it is suitable and good to weak stomach. it is good for you to buy it when going to the market." This advertisement poem is even now a comparatively successful advertising example with enough promotion and description of the goods.

\section{Interesting and funny ancient Chinese print advertisements}

With the invention and application of Chinese printing, print advertising began to appear in ancient China. Ancient Chinese print advertisements include book and bookstore ads, ad pictures, wood-block New Year pictures, artistic illustrations, and other advertising forms. Print advertising is a new form with the emergence of engraving printing technique.

The earliest print advertisement in China is the engraving print ad of Liu's needle store in the North Song Dynasty. It has reasonable layout and rigorous composition. A myth is made as a logo to denote superior quality and technique of the product in order to win the confidence from the consumers in the product. This ad is the oldest print advertisement discovered in the world.

With the further development of China's printing, there appeared the copper plate and the movable type of print advertising. In the Yuan Dynasty, merchants began to print the ads on the wrapping paper. An advertisement printed in 
paper was unearthed in Yuanling of Hunan Province. On the right it was printed vertically,

"Wei family is opposite to the Dani Temple of White Tower Street of Shengping block in Tanzhou. We produce the first-class bright red, purple and other oil paints. If you guests are willing to text them, you can find the difference. Please remember the tall red-letter sign in front of our house."

On the left it was vertically printed,

"please notice the mark of credential font of Yuanrizu store"

This is the advertisement for a paint shop in Tanzhou. With concise statement, it indicates the full address of the store, the types of goods, the quality and features. It is a relatively complete and typical print advertisement.

In the Ming and Qing period, there appeared in China chromatic printing wooden New Year advertisements and posters, instruction sheet, etc. Since the emergence of print advertising, our earliest advertising designers have been particular about the design of layout in order to achieve the purpose of effective dissemination of advertising messages.

\section{Ancient Chinese hall decoration advertisements with national characteristics}

Hall decoration advertisement is generally used to indicate the ads with special decorations in the hall of a store, a pub or a tea house. The decorated shed, foliaged gateway, flowers of all seasons, handwritings and paintings of some celebrities, and lanterns which can not only work as ornaments but also function as marks of industry are all the good cases in points. According to a book on history,

"Now the same is with the tea houses in Hangzhou. They have flowers of all seasons and paintings and handwritings of celebrities to decorate the houses."

Restaurants always suspend the portraits of Drunken Master Liu Ling and Li Bai. Just because there exists such a type of advertisements, advertisements in ancient Chinese society are more artistically attractive with distinguishing features and folk cultural characteristics.

\section{References}

Fan, Wei. (2004). Ancient Chinese Advertising Design. Yuelu Press.

Liu, Jialin. (2004). A New History of Chinese and foreign advertising, Jinan University Press.

Yang, Haijun. (2006). World Advertising History. Wuhan University Press.

You, Guoqing. (2006). Talking about advertising with the Ancients. Star Press.

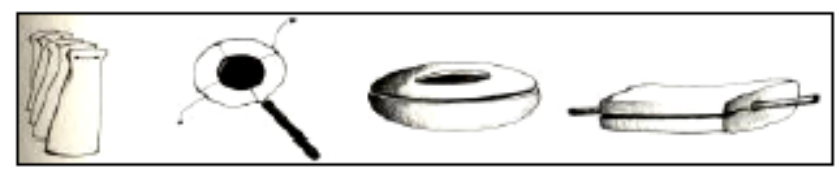

Figure 1. Jinggui, Peddler's manual Yunluo,

Chuanbell (Hucheng), Bangzi

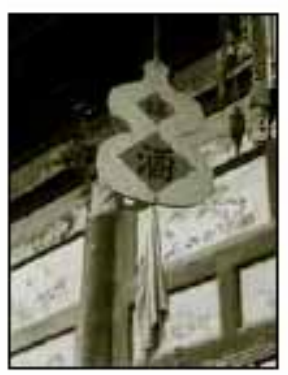

Figure 2. Wine poster 